\title{
Complications of Tonsillectomy, Adenoidectomy and Adenotonsillectomy in Chittagong Medical College Hospital
}

\author{
Abdul Qayum Chowdhury ${ }^{*}$ \\ Dhanenioy Majumder ${ }^{2}$ \\ Jishu Deb Nath ${ }^{3}$
}

'Department of Otolaryngology \& Head Neck Surgery Chattagram Maa-O-Shishu Hospital Medical College Chittagong, Bangladesh.

${ }^{2}$ Department of Otolaryngology \& Head Neck Surgery Southern Medical College

Chittagong, Bangladesh.

${ }^{3}$ Department of Medicine

Chattagram Maa-O-Shishu Hospital Medical College Chittagong, Bangladesh.
*Correspondence to:

Abdul Qayum Chowdhury Associate Professor

Chattagram Maa-O-Shishu Hospital Medical College

Chittagong, Bangladesh

Mobile : +8801711120017

Email : qayumchowdhury@yahoo.com

\begin{abstract}
It is a prospective study is done with materials of 100 cases of Tonsillectomy patient giving Proper attention to age, sex, Indication of operation, Clinical Presentation, Duration of Operation ,Post operative complications. Altogether 100 Patients of whom 54 were male and 46 female, collected for a period of 6 months from $16^{\text {th }}$ July 2001 to $15^{\text {th }}$ January 2002 with maximum age group $48 \%$ were of $20+$ years and a sex ratio of Male: female 1.17:1 were included in the series the commonest indication is Recurrent tonsillitis was $83 \%$. Among them clinical presentation, Patients presented with recurrent pain in throat (85\%), History of Fever in $62 \%$ and difficulty in swallowing in $46 \%$. Regarding duration of operation $40 \%$ Patients were operation within 30 to 39 minutes, $31 \%$ patients were operated within 40 to 49 minutes. In this Series, Complications that encountered after operation were hemorrhages both reactionary and secondary $1 \%$ and $2 \%$ respectively, operative local trauma in $4 \%$ cases and local infection in tonsillar bed in $6 \%$ cases .In this Series one patient needed second time general anaesthesia.
\end{abstract}

\section{Key words}

Complications of tonsillectomy; adenoidectomy; adenotonsillectomy.

\section{INTRODUCTION}

Tonsillectomy, adenoidectomy and adenotonsillectomy are commonly performed ENT operations in this country. In comparison to the frequency in which these operations are done in developed countries U.K and USA. it is much less frequently done in Bangladesh. The exact number of these operation done in this country is not yet available.

Some form of tonsil surgery was first attempted as early as 3000 B.C(Ritter,1967) tonsillectomy is the most frequently performed operation in the USA. In 1985.these becomes the $4^{\text {th }}$ most frequently performed operation in the United States. According to the JAMA it comprises $10 \%$ of all operations in the USA ${ }^{1}$. In 1985.these becomes the $4^{\text {th }}$ most frequently performed procedure comprising only $2.5 \%$ of all operations ${ }^{2}$.

Tonsillectomy remains of the most common surgical procedures performed in the world. One of the most significant complication is post operative hemorrhage. A ten years retrospective study showed that seven of the 750 patients(.93\%) required a second general anesthesia to control hemorrhage ${ }^{3}$.

Another retrospective study showed that the incidence of hemorrhage in non selected patient requiring surgical treatment after adenoidectomy or tonsillectomy or without adenoidectomy, post operative bleeding from tonsillar fossa $(2.94 \%)$,received blood transfusion( $0.07 \%$ ), the latest bleeding occurred 6 days (adenoidectomy) and 18 days (tonsillectomy) after surgery.

A Prospective study with 1090 patients under going surgery for investigating whether the following factors like age, sex, method. haemostasis. premedication, month of operations and experience of the Surgeon has influence on post operative haemorrhage. That study revealed these factors may have influence post operative haemorrhage ${ }^{4}$. 
A retrospective study with 4,848 patient was carried out to evaluate the age specific incidence of post tonsillectomy haemorrhage that required surgical treatment and found that post tonsillectomy heamorrhage occurred significantly more often in the adult group $(3.9 \mathrm{vs} 1.6 \% \mathrm{P}<0.001)$ than in the pediatric group. In the context of sex. post tonsillectomy haemorrhage was significantly more common in males 5 .

When the population on USA was about 220 million whereas about 200.000 tonsillectomy and adenoidectomy operation were performed combinedly or separately including all ages annually in $\mathrm{UK}^{6}$. The notes 143 consecutive children having tonsillectomy, adenoidectomy and adenotonsillectomy were analysed retrospectively determine complication rates. Of the total number of children $5.6 \%$ had at least one complication the most common of which was haemorrhages ${ }^{7}$.

In another prospective study morbidity and complication associated with tonsillectomy and adenotonsillectomy include severe otalgia,pyrexia,odynophagia and haemorrhage ${ }^{8}$. Hospital admission of adenotonsillectomy in Scotland still accounts for a sizable proportion of overall pediatric admissions below the age of 14 years ${ }^{9}$. Day case surgery is increasingly being advocated for many procedures and several series of day case adenotonsillectomy have been published ${ }^{10}$. Complication rates for day case tonsillectomy, adenoidectomy and adenotonsillectomy ranges.

From $0.28 \%$ to $4.4 \%$ for haemorrhage, $1.3 \%$ for fever ${ }^{11}$. Tonsillectomy is reported usually to be a simple and uncomplicated operation $^{12}$. Some complication are secondary to anaesthesia which include myocardial instability, laryngeal. trauma, aspiration of blood or mucous.

Besides anaesthetic cause, the most common factor responsible for death following tonsillectomy is haemorrhage either primary, reactionary or secondary, specially when it remains unrecognised and not treated timly ${ }^{13}$.

Aims \& Objectives -

The aims and objectives were

1. To Find out the various post operative Complications in Tonsillectomy, Adenoidectomy and Adenotonsillectomy.

2. To find out the duration of operation

3. To find out the relation of post Tonsillectomy hemorrhage with age and sex.

\section{MATERIALS \& METHODS}

It is a prospective study carried out in the in patient department of otolaryngology and head neck surgery of Chittagong Medical College from $16^{\text {th }}$ July 2001 to $15^{\text {th }}$ January 2002.Among the operated patients 100 cases were randomly selected. Diagnosis was confirmed by history, clinical feature and examination. After noting the selection criteria and recording the information from the cases on a standard proforma. Particular cases was taken to exclude the cases with (a) Recent history of upper respiratory tract infection and (b) history of bleeding tendency in patient or in family.

\section{OBSERVATIONS \& RESULTS}

Table 1: Age distribution of underwent tonsillectomy, adenoidectomy and adenotonsillectomy (n-100), Age(years).

\begin{tabular}{lcccc} 
Age & $0-9$ & $10-19$ & $20+$ & Total \\
Tonsillectomy & 2 & 33 & 48 & 83 \\
Adenotonsillectomy & 9 & 6 & 0 & 15 \\
Adenoidectomy & 2 & 0 & 0 & 2 \\
Total & 13 & 39 & 48 & 100 \\
\hline
\end{tabular}

out of 100 operated patients maximum age group $48 \%$ were of $20+$ years. Next to that $39 \%$ were of in the age group 1019 years. The age of the youngest patient was 3 years \& 6 months and that of oldest one was 42 years Among the operations. only tonsillectomy was done in $83 \%$ patients and adenotonsillectomy was done in $15 \%$ patients.

Table 2 : Sex distribution of operated patients $(n-100)$

\begin{tabular}{lcc} 
Sex & Number of patients & Percentage \\
Male & 54 & 54 \\
Female & 46 & 46 \\
Total & 100 & 100 \\
\hline
\end{tabular}

Among 100 patients ,54\% were male and $46 \%$ were female with a male to female ratio $1.17: 1$.

Table 3: Indications of operation $(\mathrm{n}=100)$

\begin{tabular}{lcc} 
Diagnosis & Number of patients & Percentage \\
$\begin{array}{l}\text { Recurrent tonsillitis } \\
\begin{array}{l}\text { Enlarged adenoid \& tonsils causing } \\
\text { obstructive symptoms and infection }\end{array}\end{array}$ & 83 & 83 \\
$\begin{array}{l}\text { Persistence of CSOM, OME } \\
\text { Where adenoid }\end{array}$ & 15 \\
$\begin{array}{l}\text { and tonsil was thought to be the } \\
\text { cause of disease }\end{array}$ & 02 & 02 \\
Total & 100 & 100 \\
\hline
\end{tabular}

Among the indications of operations, Recurrent tonsillitis was highest (83\%), Next to that was Enlarged adenoid \& tosile causing obstructive symptoms and infection was (15\%).

Table 4 : Presenting symptoms of the patients (n-100)

Number of patients percentage

1.Recurrent pain in throat

$85 \quad 85$

2.History of fever

62

3. Difficulty in swallowing

4.Nasal blokage / mouth breathing

46

5.Pain in ear

17

6.Nasal discharge

18

7. Deafness

8. Difficulty of breathing at night 
A patient may have more than one complain. Among the presenting symptoms, maximum patients $(85 \%)$ complained of recurrent pain in throat. This was following by History of fever in $62 \%$ and difficulty in swallowing in $46 \%$ patients.

Table 5: Duration of operation(including anaesthetic time) $(n=100)$

\begin{tabular}{ccc} 
Number of Patient & $\begin{array}{c}\text { Duration of operation in } \\
\text { (minutes) }\end{array}$ & Percentage \\
40 & $30-39$ & 40 \\
31 & $40-49$ & 31 \\
17 & $20-29$ & 17 \\
1 & 70 and above & 1 \\
\hline
\end{tabular}

Regarding duration of operation ,40\% patients were operated within 30 to 39 minutes, $31 \%$ patients were operated within 40 to 49 minutes and $17 \%$ patients were operated within 20 to 29 minutes. But in $01 \%$ case the duration of operation was 70 minutes and above.

Table 6: Post operative complications $(\mathrm{n}=100)$.

\begin{tabular}{|c|c|c|}
\hline Complications & Number of patients & Percentage \\
\hline 1.Haemorrhage: & 01 & 01 \\
\hline $\begin{array}{l}\text { Reactionary haemorrhage, } \\
\text { Secondary haemorrhage }\end{array}$ & 02 & 02 \\
\hline $\begin{array}{l}\text { 2.Local infection in tonsillar bed } \\
\text { 3.Operative trauma to lip, }\end{array}$ & 06 & 06 \\
\hline tongue,posterior pillar of tonsil & 04 & 04 \\
\hline
\end{tabular}

Complications that encountered after operation were haemorrhages both reactionary and secondary, $1 \%$ and $2 \%$ respectively, Operative local trauma in $4 \%$ cases and local infection in tonsillar bed in $6 \%$ cases.

In this series one patient needed second time general anaesthesia.

Table 7: Sex distribution of patient with post operative haemorrhage $(n=3)$.

$\begin{array}{lcc}\text { Sex } & \text { No of haemorrhage } & \text { percentage } \\ \text { Male } & 2 & 66.66 \\ \text { Female } & 1 & 33.33\end{array}$

Here out of 3 cases of post operative haemorrhage two case $(66.66 \%)$ were male and one was female(33.33\%).

\section{DISCUSSION}

This study was carried out to find out the complications of tonsillectomy, adenoidectomy and adenotonsillectomy.

Among the 100 patients, 54 were male and 46 were female.The male female ratio was $1.17: 1$, Tonsillectomy was done in 83 cases.

Adenotonsillectomy in 15 cause and adenoidectomy in 2 cases.
In this series tonsillectomy was carried out in a bulk of patient (48\%) aged 20 yaars and above.Though tonsillectomy is a common surgery in paediatric age group ${ }^{14}$.

In this series total incidence of post operative bleeding was $3.0 \%$. The incidence of reactionary hemorrhage was $1 \%$ and secondary hemorrhage was $2 \%$. This mimic the findings of curred in kumar Pronoy ${ }^{14}$, Who studies 100 tonsillectomy, adenoidectomy and adenotonsillectomy patient and found reactionary hemorrhage in $1 \%$ and secondary hemorrhage in $2 \%$. This also nearly mimic the findings of Richmond $\mathrm{KH}$ et $\mathrm{al}^{15}$. Who studied 784 tonsillectomy and adenotonsillectomy patients and found reactionary hemorrhage in $1.0 \%$ children and secondary hemorrhage in $2.0 \%$ children. This study also nearly mimics the finding of Chowdhury $\mathrm{k}$ et $\mathrm{al}^{16}$. Who studied 6842 post operative patients and found total incidence of post operative hemorrhage was $2.5 \%$.

The incidence of post operative hemorrhage in this study is slightly higher than the study of Crysdale WS et $a^{17}$. who showed $2.15 \%$. on the other hand Kendrick D et $\mathrm{al}^{7}$. Study showed $4.36 \%$. Children developed post operative hemorrhage which is higher than the present study.

In this series out of 3 cases of post operative hemorrhage $2(66.66 \%)$ cases was seen in 10-19 years and one case $(33.33 \%)$ was seen in less than 9 years age group, Which is more or less similar to the finding of Kumar Pronoy ${ }^{18}$.

In relation to sex,out of 3 cases of post operative hemorrhage 2 cases $(66.66 \%)$ were male \& $1(33.33 \%)$ was female. This is in accordance with author ${ }^{19}$.

Regarding the indication of Tonsillectomy operation, the commonest indication of Tonsillectomy in this series was recurrent tonsillitis which is in accordance with the findings of Joarder $\mathrm{AH}^{19}$. In this Series the duration of surgery was 33-39 minutes in $40 \%$ patients and in 31\% requires $40-49$ minutes for completion of surgery. This has a similarity with authors ${ }^{14,19}$.

In this series secondary hemorrhage was recorded in 2 cases $(2.00 \%)$. Which is more or less similar to the findings of richmond $\mathrm{KH}$ et al.(2.00\%) Joarder $\mathrm{AH}(2.00 \%)$ and Kumar Pronoy $(2.00 \%)$.

Regarding post operative hemorrhage $3.0 \%$ occurred in this series which is more or less similar to kumar Pronoy (3.0\%) \& nearly similar to chowdhury $\mathrm{K}$ et al.series $(2.5 \%)$ and Crysdale WS et al. series(2.15\%). But dissimilar to the series of Lee WC at al.(8.9\%) and Mutz 1 al.(1.25\%).

In this series $1(1.00 \%)$ of the 100 post operative patient required a second general anaesthesia to control hemorrhage, Which is more or less similar to the finding of Kumar Pronoy $(1.00 \%)$ and very close to the study of Schdroeder WA (0.93) and far random the study of Richmond $\mathrm{KH}$ et al.(2.17) and Crysdate WS et al.(0.06\%).

This Study showed that 6.(6.0\%) patients developed infection in the tonsillar bed postoperatively, of which is very close to the study of Rafiquzzaman $\mathrm{M}^{19}$. and kumar Pronoy ${ }^{14}$ who showed $5 \%$ tonsillar bed infection. 
Whereas Joarder AH study showed that $2.0 \%$ patient developed patient developed local infection in tonsillar bed. kendrick D at $\mathrm{al}^{7}$ study showed that $1.50 \%$ children developed fever post operatively. The present series also noted trauma to upper lip, injury to tongue and injury to the posterior pillar of tonsil in $4 \%$ cases. Wheras in Joarder AH showed that various injuries coccurred in $8.0 \%$ cases Kumar Pronoy showed 3.0\% and Rafiquzzaman Md showed that in $2.5 \%$ cases various minor trauma takes place. All these injuries can be explained by the fact that a large number of operations were carried out by junior or trainee surgeons and their less experience resulted the trauma.

\section{CONCLUSION}

From this study we can conclude that hemorrhage after tonsillectomy may occur in few occasions and it is more common in male patients. The other complications like tonsillar bed infection \& Trauma to lip, tongue,palate and posterior pharyngeal wall may occur in a significant number of cases.

However the results of the present study may not be the representative of overall situation as it was carried out with a limited number of patient in a limited span of time.

\section{DISCLOSURE}

All the authors declared no competing interest.

\section{REFERENCES}

1. Tonsillectomy morbidity (Editorial)JAMA 1965;194:824

2. West Midlands regional Health Authority. Hospital Activity Analysis Figures, 1965,1985.

3. Schroeder WA Jr.Post tonsillectomy haemorrhage: A ten year retrospective study MO Med 1995;92(9):592-595.

4. Roberts SC, Jayaramachandran S, Raine CH.A prospective study of factors which may predispose to post operative tonsillar fossa haemorr hage.Clin Otolaryngol $1992 ; 17: 13-17$.

5. Windfuhr,-J-P:chen,Y-S Incidence of post Tonsillectomy haemorrhage in children and adults; a study of 4,848 patients, Ear-Nose Throat -J 2002;81(9):626-632.

6. Mawson SR. Disease of the tonsils and adenoids.In: groves BJ. editor. The pharynx and Larynx. Scott-Brown's Disease of the Ear, Nose and Throat,, $5^{\text {th }}$ edn.London : Butterwoth:1979; 141.

7. kendrick D and Gibbin K.An audit of the complications of paediaric tonsillectomy, adenoidectomy and adenotonsillectomy, Clin Otolaryngol 1993;18:115-117.

8. Zakirullah. Post tonsillectomy and adenotonsillectomy morbidity and complications at Destrict Head quarter Hospital Daggar. J-Ayub-med Coll-Abbottabad 2001;13(3):4-6.

9. Bussuttil A, kerr AIG, Loga RW, Iron deficiency in children undergoing adenotonsillectomy. J Laryngol otol 1979;93:4958.

10. Guida RA, Mattucci K. Tonsillectomy and adenodectomy; an in patient or out patient procedure, Laryngoscope 1989;100:491-493.

11. Carithers JS,Gebhart DE, Willium J. Post operative risk of paediatric tonsilloadenoidectomy.Laryngoscope 1987;97:422429

12. Tami TA,Barket GS Laylor R. Post tonsillectomy bleeding an evaluation of risk factors, laryngoscope 1987;97:13071311.

13. Tate N. Deaths from Tonsillectomy(letter). lancet ii :1963;1090-1091

14. Kumar Pronoy,An audit of the Complications of Paediatric Tonsillectomy, Adenoidectomy and Adenotonsillectomy in IPGMR(Former) and DMCH. Dhaka ( a study of 100 cases) Dissertation Dhaka Bangladesh College of Physicians and surgeons.1997.

15. Rechmond KH, Wetmore RF, Baranak C.Post operative complications following tonssillectomy and adenoidectomy who is at risk.Int JPediatr otorhinoloaryngol 1987;13(2):117-124.

16. Chowdhury k.Tewfik TI, Schloss MD, Post tonsillectomy and adenoidectomy haemorrhage, J Otoryngol,1988;17(1):4649.

17. Grysdale WS, Russel D. Complications of tonsillectomy and adenoidectomy in 9409 children observed over night. Can Med Assoc J $1986 ; 135(10): 1139-1142$.

18 Joarder AH post tonsillectomy complications A study of 50 cases(Dissertation) Dhaka,Bangladesh College of Physicians and Surgeons.1990.

19. Rafiquzzaman M.Prophylatic single dose of antibiotic in tonsillectomy study of 100 cases-(Dissertation) Dhaka.Banladesh College of Physicians and Surgeons.1994. 